\title{
Uses and Functions of Teaser Campaigns in Advertising and Promotion: A Content Analysis of Newspaper and Television Advertisements in India
}

\author{
Kulveen $\operatorname{Trehan}^{1 *}$ and G.S. Maan ${ }^{2}$ \\ ${ }^{1}$ University School of Mass Communication, Guru Gobind Singh Indraprastha University, New Delhi, India \\ ${ }^{2}$ Director, Centre For Advanced Media Studies, Punjabi University Patiala, India
}

\begin{abstract}
The paper attempts to analyze the significance of teaser advertising in integrated brand promotion. This study examines the communication objectives and functions of teaser campaigns in above the line media. A critical exploration of the nature, composition and uses of the campaigns provides significant indications towards the scope of teaser advertising in particular and novel creative executions in general. The results suggest that teaser campaigns now, extend themselves beyond their principle function of 'curiosity' and are created largely with the twin objective of arousal of interest and consumer engagement. Both newspaper and television campaigns show use of both verbal and visual elements to tease the audience.
\end{abstract}

Keywords: Teaser campaigns; Mystery; Curiosity; Knowledge gap; Brand interest; Attention; Creative execution; Media innovations

\section{Introduction}

India with its wide and diverse consumer base became the most potent market. As product continued to multiply, need for promotion heightened. Advertising emerged as the primary driver of promotion in the mass mediated environment. Advertising with its multidimensional nature and scope has been able to perform the functions of promotion across product categories and consumer needs, interests and motives. Diverse roles of advertising expanded its creative spectrum leading to continuous development of newer forms of advertising either on the basis of its area, purpose or the creative execution format. Advertising has evolved from direct sell product advertising to innovative forms like teaser advertising in order to create a unique perceptual space in the minds of the audiences.

Teaser advertising is a term used for an advertising campaign where series of ads are presented to the consumer without revealing the complete identity of the product or brand till the last ad. Teaser advertising campaigns consist of two parts: series of teaser ads (one or more than one) and a revealer ad. The series of advertisements building the systemic excitement around the brand are called teaser ads and the final advertisement disclosing the identity and characteristics of the brand is called the revealer.

According to the Business dictionary, "a teaser ad is an ad that does not reveal full information about the advertiser or the product; teaser ads may consist of an unfinished ad story or a partial view of the advertised product, and may even pertain to an unspecified product category".

\section{Review of Literature}

Kover [1] finds strong mention of teaser advertising to hook the viewers by the creative professionals in his studies. He noted that 'a teaser gives incomplete information that entices another to seek to unravel or to trap the concealer into subsequent acts of discovery'. Vallalderas in her book [2] categorises teaser as a separate type of advertising. While enlisting the types of print ads in India, she states that the teaser are a series of ads that may appear in the same newspaper on the same day or on consecutive days which reveal the advertisers message in stages. Teaser appeals were analysed in various product categories in USA (Belch 2003). Yeshin [3] categorises teaser advertising as a creative execution style, commonly used by new products to create an element of intrigue and curiosity to build anticipation and excitement. For practical application and theoretical uniformity, the researcher regards teaser advertising as a creative execution format and curiosity [4] as an appeal. Kardes [5] categorised types of advertisements on the basis of attention function. According to him, teaser ads are prevention focused ads that use ambiguity, confusion and uncertainty to reduce resistance to persuasion. These ads gain consumer attention and encourage open mindedness through building curiosity and interest, introducing a surprising piece of information or creating confusion.

Hung [6] in his examination of music-visual relationship in audiovisual advertising, television in particular studied how music (element of TV advertising) influences communication of ad messages in teaser ads.

Menon and Soman [7] studied the cues of curiosity and its impact on consumer motivation and learning in relation to internet advertising. The study shows that ad strategies using curiosity as the dominant message strategies result in better and more focused memory and comprehension of new product information the findings suggest that a moderate time gap is optimal for curiosity generation, elaboration and learning.

PSI [8] commissioned a study on post campaign impact evaluation of the Balbir Pasha Teaser campaign on AIDS awareness in the country. Balbir Pasha-a fictional character was created for a four month long teaser campaign. The campaign was run in newspapers, radio, television and outdoor media in Mumbai, the epicenter of HIV AIDS in the country. The impact study revealed that the campaign had

*Corresponding author: Kulveen Trehan, Assistant Professor, University Schoo of Mass Communication, Guru Gobind Singh Indraprastha University, New Delhi, India, E-mail: Kulveentrehan.ipu@gmail.com

Received November 19, 2012; Accepted January 17, 2013; Published January 24, 2013

Citation: Trehan K, Maan GS (2013) Uses and Functions of Teaser Campaigns in Advertising and Promotion: A Content Analysis of Newspaper and Television Advertisements in India. J Mass Communicat Journalism 3:145. doi:10.4172/2165 7912.1000145

Copyright: (C) 2013 Trehan K, et al. This is an open-access article distributed under the terms of the Creative Commons Attribution License, which permits unrestricted use, distribution, and reproduction in any medium, provided the original author and source are credited. 
significant impact on the members of the target group and was able to change their attitude towards the disease.

A case study 'Relaunch of Frooti-the Digen Verma campaign established the effectiveness of using teaser campaigns in India. In January 2001 Everest Integrated Communications created a innovative teaser campaign with a brand new brand persona "Digen Verma" Since the strategy revolved around creating a connect with a factious character instead of celebrities. In order to communicate its brand mascot and position it differentially from its competitors, Parle Agrochemicals for its mango drink Frooti a multimedia teaser campaign was especially designed around the character. The teaser campaign included print ads, TVC's, outdoor media, offline promotions and online advertisements. This teaser campaign aimed to generate voluminous interest by building hype around the mysterious character, the target segment for the campaign was teenagers; therefore the media vehicle for teaser advertising was specifically aimed at them [9].

\section{Objectives of the Study}

1) To gain insight into the nature and composition of teaser campaigns created and executed in Indian advertising

2) To know the most popular visual and verbal conveyors of teaser advertising

3) To understand the branding and communication functions of teaser campaigns in print and television

\section{Methodology}

The research was undertaken to gain insight into this specific form of advertising in print and television media and to know its effectiveness and functions. The purpose of the study was to critically analyze teaser advertising in print and television media. The foremost objectives of the study were to know the elements, devices and typology of teaser campaigns in the two predominant advertising media in India [10]. One newspaper and television channel was sufficient to provide the required data because the same teaser campaign appears in various newspapers or TV channels at one time. This study considers the teaser campaigns in a widely circulated newspaper The Hindustan Times [11] from $1^{\text {st }}$ January 2007-31 ${ }^{\text {st }}$ December 2009 and television channel Sony Entertainment Channel [12] from 1st January 2007-31 $1^{\text {st }}$ December 2009. The researcher obtained teaser advertisements from the newspaper and television channel of the year 2007, 2008 and 2009.

All the morning editions of the English daily newspaper, The Hindustan Times along with the supplement were collected to obtain the teaser advertising campaigns, the unit of analysis for the study. A total of 57 teaser campaigns were found in all the 1095 newspapers. Those 57 teaser campaigns contained 191 advertisements including 134 teaser ads and 57 final revealer advertisements.

Adventure [13] was used to obtain the teaser timeline of Sony Entertainment Television Channel in India. After seeing the timeline of the campaigns ( names and date of occurrence), creative showcase [14] from www.agencyfaqs.com were collected for a period of three years (2008, 2009 and 2010) to extract the all teaser advertising campaigns broadcast on the television channel. A total of 30 teaser campaigns were found. Those 30 teaser campaigns contained 128 commercials including the 98 teaser and the 30 final revealer advertisements.

\section{Content categories}

I. Product Category: Classification of products on basis of their attributes and structure
II. Product Type: Specific type of good, service or idea based organizations

III. Place of Creative Execution: Advertising and promotion agencies and departments where teaser campaigns are conceptualize, planned and executed.

IV. PLC stage: The stage at which teaser campaign is used by a product/brand during its life cycle

V.a) Teaser element in newspaper ads: The advertising verbal and visual conveyor used as the primary element to tease the audience.

\section{b) Teaser element in television commercials}

\section{Teaser Typology}

a) Classic teasers: advertising campaigns in which all the teaser ads do not reveal anything about the product, the advertiser or the message content of the succeeding ads in the campaign. Here, there is no clue or suggestion about the advertised product or the sponsor.

b) Partial teasers: advertising campaigns in which some identity symbol of the product or the brand is given but without providing any idea about the concept or the theme of the succeeding ads in the campaign. Here, sponsors identity is present but without the product identity.

VII. Revealer advertisement format: The ad execution format used to create the final revealer advertisement in a teaser campaign

VIII. TAC duration: Total running time of the teaser campaign or the time period for which the campaign is run from start to finish.

a) 1-3 days b) 4-9 days c) 10-15 days d) 16-30 days e) 30 days and above

IX. Dominant objective of teaser advertising: The most visible objective established during the planning and execution of teaser campaigns.

X. Teaser device: Words and phrases that connect one teaser ad with the other in the campaign For eg: coming soon, turn over, wait and watch , ..., more to come, know more , keep reading etc.

XI. Continuity of a story: Telling one complete story through series of teaser ads and the final revealer in the campaign

XII. Linkage with the brand: Various message execution strategies that are reflected in the teaser campaign to strengthen its linkage with the brand's ad plan.

\section{Brand Building Functions}

a) Brand Presence: spreading awareness about the existence of the brand.

b) Brand Interest: curiosity about the brand in the minds of the buying prospects.

c) Brand Extension: elongating the brand life cycle by modifying the existing product.

d) Brand Image: perception about the brand in the minds of the buying prospects.

e)Category Need: creation of requirement/desire for a product category in general. 
Citation: Trehan K, Maan GS (2013) Uses and Functions of Teaser Campaigns in Advertising and Promotion: A Content Analysis of Newspaper and Television Advertisements in India. J Mass Communicat Journalism 3:145. doi:10.4172/2165-7912.1000145

Page 3 of 8

\section{Results and Discussion}

It was clear from the findings that teaser campaigns are increasing being executed in both newspapers and television. 57 teaser campaigns in the newspaper and 30 teaser campaigns on television channel were found in three years' period of the study (Table 1).

Most of the teaser campaigns in newspaper and television were created by full-fledged large scale advertising agencies. $60 \%$ of the total campaigns in newspaper and $90 \%$ in television were created by large agencies. In fact a large number of these campaigns were created by Ogilvy \& Mather, the top most ad agency in India. In the newspaper, Ala-Carte agencies (26.3\%) advertising also did these campaigns. Agencies like Orchard, Aksh created teasers for national, local brands and shopping malls in Delhi/NCR. Even government agencies (14\%) have done teaser campaigns in the newspaper. It can be assumed that Directorate of Audio Visual Publicity is also no longer reluctant to innovate. DAVP infamous for its boring, run of the mill advertising, often direct and announcement like also created teaser campaigns for its mega health communication project 'AIDS Awareness' . Significant to note was that it created campaigns based on different objectives and elements each time.

Teaser advertising on television remained majorly a creative job of the mega full size advertising agencies. Only $7 \%$ and $3 \%$ campaigns were done by exclusive media agencies or creative boutiques and departments agencies of the public sector establishments.

It is clear from the results that $90 \%$ of the campaigns during the time studied were done by the top three ad agencies in India. AlaCarte agencies and government ad departments are not creating teaser campaigns for television to that extent (Figure 1). It may be due to the reason that since television campaigns entail considerable production cost and are creatively less flexible in comparison to print and outdoor media therefore small agencies and conventional advertisers/agencies refrain from innovative forms of advertising fearing a boomerang effect

\begin{tabular}{|l|c|c|c|c|c|c|}
\hline & \multicolumn{3}{|c|}{ Newspaper } & \multicolumn{3}{c|}{ Television } \\
\hline $\begin{array}{l}\text { Teaser } \\
\text { campaign makers }\end{array}$ & figure & Percent & Cumulative & Freq & Percent & Cumulative \\
\hline Full size agency & 34 & 59.6 & 59.6 & 27 & 90.0 & 90.0 \\
\hline Ala-Carte agency & 15 & 26.3 & 86.0 & 2 & 6.7 & 96.7 \\
\hline $\begin{array}{l}\text { Government } \\
\text { agency }\end{array}$ & 8 & 14.0 & 100.0 & 1 & 3.3 & 100.0 \\
\hline Total & 57 & 100.0 & & 30 & 100.0 & \\
\hline
\end{tabular}

Table 1: Frequencies of teaser campaigns done by various advertising agencies/ departments.

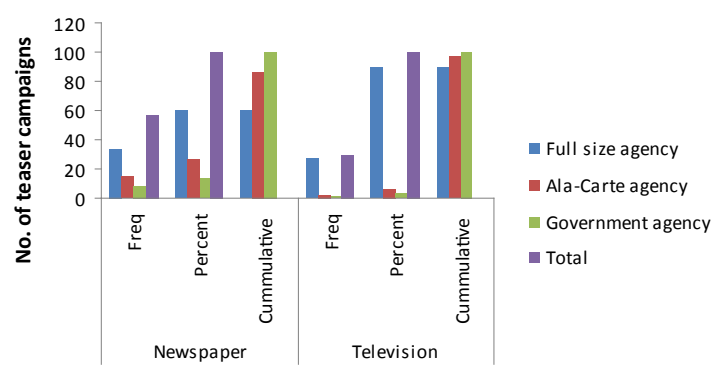

Place of creative execution

Figure 1: Distribution of teaser campaigns done by different ad agencies/ deptt.

\begin{tabular}{|l|c|c|c|c|c|c|}
\hline & \multicolumn{3}{|c|}{ Newspaper } & \multicolumn{3}{c|}{ Television } \\
\hline Stage of plc & Freq & Percent & Cumulative & Freq & Percent & Cumulative \\
\hline Introduction & 22 & 38.6 & 38.6 & 10 & 33.3 & 33.3 \\
\hline Growth & 12 & 21.1 & 59.6 & 5 & 16.7 & 50.0 \\
\hline Maturity & 9 & 15.8 & 75.4 & 6 & 20.0 & 70.0 \\
\hline Revival & 14 & 24.6 & 100.0 & 9 & 30.0 & 100.0 \\
\hline Total & 57 & 100.0 & & 30 & 100.0 & \\
\hline
\end{tabular}

Table 2: Frequencies of teaser execution at the PLC stage in The Hindustan Times and Sony Entertainment Channel.

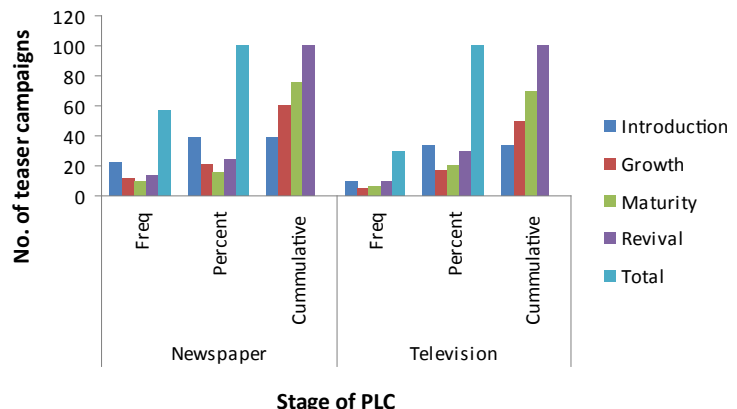

Figure 2: Distribution of teaser campaigns done at various stages of product life cycle.

with heavy losses (Table 2).

\section{PLC : Product life cycle}

It shows that teasers on both the media were primarily used to introduce a new product in the market or to revive an existing brand. These two stages together found $63.2 \%$ and $63.3 \%$ campaign in the newspaper and the television channel respectively (Figure 2).

Around $39 \%$ of products used teaser campaigns to introduce the product in the market or launch the product for the first time, whereas $25 \%$ campaigns were created to revive a diminishing product by extending its product line through introduction of new variant. For e.g. Dove, Pantene, Sach ka Samna, Airtel extended its line by creating a teaser campaign for Airtel DTH, The Hindustan Times extended its life cycle by a campaign for HT Mint, HT Brunch, HT Estates etc. Despite popular belief that teaser campaigns are only used to either launch a product or a brand extension, lot of campaigns like Dove, Pantene, Tata Sky were done when the product was either on an incline i.e. the sales and the consumer base of the product are growing (21\%) or during maturity when the product was trying to establish itself by branding through positioning and consolidating its market position (15\%) (Figure 2).

Likewise on the television channel, 33\% teaser campaigns were to introduce a new product for the first time in the market, whereas around $30 \%$ campaigns were intending to extend a product through a new line extension or by repositioning the existing brand to elongate the product life cycle. Thus, we see that products are using teasers for growing brands allocating far more serious and long term objectives to innovative forms of advertising (Table 3a).

The results show that in newspapers, headlines was the predominant teaser element used to build the series of teaser advertisements in the campaign $.39 \%$ of the teaser campaigns had headline as its teaser element. It was also evident from the results that more than one copy element was used as the teaser element in the campaign .44\% campaigns used a combination of both verbal and visual elements in the teaser 


\begin{tabular}{|l|c|c|c|c|}
\hline PrintAd Element & Frequency & Percent & Valid Percent & Cumulative Percent \\
\hline Headline & 22 & 38.6 & 38.6 & 38.6 \\
\hline Visual & 5 & 8.8 & 8.8 & 47.4 \\
\hline Logo & 4 & 7.0 & 7.0 & 54.4 \\
\hline Body copy & 1 & 1.8 & 1.8 & 56.1 \\
\hline $\begin{array}{l}\text { Combination of } \\
\text { more than one }\end{array}$ & 25 & 43.9 & 43.9 & 100.0 \\
\hline Total & 57 & 100.0 & 100.0 & \\
\hline
\end{tabular}

Table 3a: Frequencies of teaser element in The Hindustan Times.

\begin{tabular}{|l|c|c|c|c|}
\hline TV Ad Element & Frequency & Percent & Valid Percent & Cumulative Percent \\
\hline $\begin{array}{l}\text { (Visual And Spoken) } \\
\text { Tagline }\end{array}$ & 7 & 23.3 & 23.3 & 23.3 \\
\hline Story/Scenes & 13 & 43.3 & 43.3 & 66.7 \\
\hline Supers/Written Copy & 1 & 3.3 & 3.3 & 70.0 \\
\hline Visual Memory Device & 8 & 26.7 & 26.7 & 96.7 \\
\hline Logotype & 1 & 3.3 & 3.3 & 100.0 \\
\hline Total & 30 & 100.0 & 100.0 & \\
\hline
\end{tabular}

Table 3b: Frequencies of teaser element on Sony Entertainment Channel.

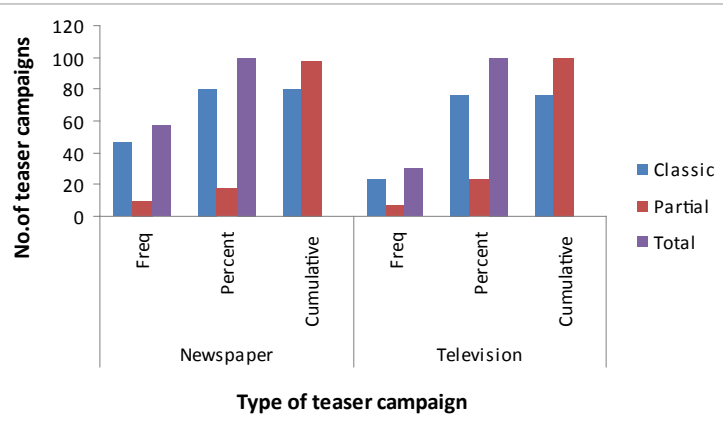

Figure 3: Distribution of types of teaser campaigns.

ads. In newspapers, maximum number of teaser campaigns had both headline and a visual (picture) as the teaser element. Therefore it was observed that campaigns had two elements (one verbal and one visual) as a teaser element to progress in continuation from one teaser ad to another. In a few campaigns, three elements (headline, visual and body copy) came (DDA, HT Mint, NACO, Hyper M) together to form a teaser element. Further descriptive analysis shows a few types of headlines were used more. Curiosity Headline, Question Headline, Declarative Headline were used in most ads. In some cases a Blind Headline was used to heighten the arousal or to augment the mystery quotient of the campaign. It was seen that logotype (7\%) and body copy (2\%) were not commonly used as teaser elements. From the results it can be inferred that print teaser campaigns relied on high attention nature of curiosity or intrigue headline, action intent of the question and statement of declarative headlines in series of teaser ads aim to inform about a new idea/object in bits and parts to fill in their knowledge gap by adding information drop by drop.

From the (Table 3b) we can see that on television; most commonly found teaser element was the scene (showing the story in bits and parts). $43 \%$ campaigns used an entire scene as one teaser element to narrate the teaser story. The story presented in a single scene acted as the teaser element in television commercials. Use of scene as teaser element implies that the intent is to heighten the interest of the audience in the story being slowing told through teasers. It aims to transform all the ad viewers into active audiences, enticing them to seek the gratification they need through media uses of the advertising campaign. Some campaigns $(23 \%)$ executed teaser ads through visual tagline or the spoken tagline. Visual memory devices $23 \%$ and visual and spoken taglines $27 \%$ also act as teaser elements in television ads. However, music in any form was not used as a teaser element in any campaign. Jingles or signature tunes were not found as solo elements of teaser ads. It was clear that unlike print, teaser advertising though television is far more integrated. The teaser campaign theme is not carried forward through an individual element of the television commercial but is embedded in the entire scene or the audiovisual narrative of the advertisement. It is interesting to note that while taglines are considered to be a high recall and recognition element, teaser campaigns are not using them to a great extent (Table 4).

As many as $81 \%$ of the total campaigns were classic teaser campaigns in the newspaper. From the results it can be argued that complete curiosity is the essence of teaser advertising in India. The creative in the advertising agencies are working on the dual maxim of guess the next ad and guess the brand in the same campaign. Unaided identity search is the bottom-line of the classic campaigns. Classic teasers can have cues hidden in the copy elements of the series of teaser advertisements. They are totally nameless campaigns offering an absolutely new idea to the audience with a sequence or story progressing into the final complete advertisement presenting both the climax of the story and the identity of the brand. Similar trends are visible on the television channel. $77 \%$ of the campaigns were classic campaigns with no visual or verbal clue given in the series of teasers used.

While majority of the campaigns were classic teaser campaigns, some were partial teaser campaigns in the sample studied. $18 \%$ and $23 \%$ campaigns were partial teaser campaigns in print and television respectively (Figure 4). Here, the audience knew either the corporate brand or the principle advertisers, but did not have a clue on what is it all about. It happened in the cases where a corporate brand was diversifying into a new sector or product category (HT Estates, Quantas, HUL, Go jivo etc.) (Table 5).

Teasers campaigns used a common connector to link all the ads in the campaign in print as well as television advertising.The data presented shows that $62 \%$ teaser campaigns in newspapers had a connecting device, generally a copy element linking all the teasers in

\begin{tabular}{|l|c|c|c|c|c|c|}
\hline & \multicolumn{3}{|c|}{ Newspaper } & \multicolumn{3}{c|}{ Television } \\
\hline Teaser Typology & Freq & Percent & Cumulative & Freq & Percent & Cumulative \\
\hline Classic & 46 & 80.7 & 80.7 & 23 & 76.7 & 76.7 \\
\hline Partial & 10 & 17.5 & 98.2 & 7 & 23.3 & 100.0 \\
\hline & 1 & 1.8 & 100.0 & & & \\
\hline Total & 57 & 100.0 & & 30 & 100.0 & \\
\hline
\end{tabular}

Table 4: Frequencies of type of teaser campaign in The Hindustan Times and Sony Entertainment Channel.

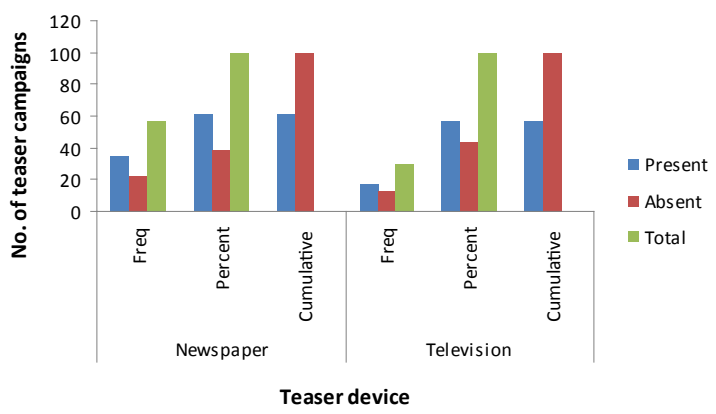

Figure 4: Distribution of teaser campaigns for teaser device. 


\begin{tabular}{|l|c|c|c|c|c|c|}
\hline & \multicolumn{3}{|c|}{ Newspaper } & \multicolumn{3}{c|}{ Television } \\
\hline Teaser Device & Freq & Percent & Cumulative & Freq & Percent & Cumulative \\
\hline Present & 35 & 61.4 & 61.4 & 17 & 56.7 & 56.7 \\
\hline Absent & 22 & 38.6 & 100.0 & 13 & 43.3 & 100.0 \\
\hline Total & 57 & 100.0 & & 30 & 100.0 & \\
\hline
\end{tabular}

Table 5: Frequencies of teaser device in The Hindustan Times and Sony Entertainment Channel.

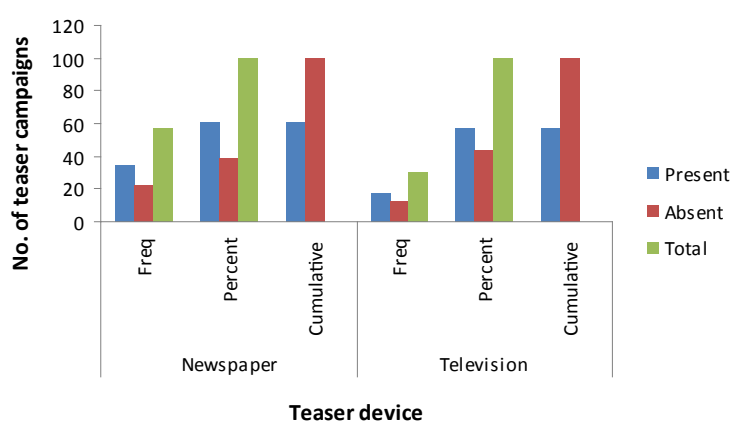

Figure 5: Distribution of teaser campaigns for teaser device.

\begin{tabular}{|l|c|c|c|c|c|c|}
\hline & \multicolumn{3}{|c|}{ Newspaper } & \multicolumn{3}{c|}{ Television } \\
\hline Continuity & Freq & Percent & Cumulative & Freq & Percent & Cumulative \\
\hline Present & 20 & 35.1 & 35.1 & 13 & 43.3 & 43.3 \\
\hline Absent & 37 & 64.9 & 100.0 & 17 & 56.7 & 100.0 \\
\hline Total & 57 & 100.0 & & 30 & 100.0 & \\
\hline
\end{tabular}

Table 6: Frequencies of continuity of a story in teaser campaign in The Hindustan Times and Sony Entertainment Channel.

the campaign. Further analysis showed that the device used were verbal elements like buzz words, action words and emotive words. Commonly used teaser copy devices were action words e.g: turn to page no $\mathrm{x}$ to lead the audience to the next teaser. Buzz words and phrases like coming soon, know more wait and watch, watch this space, acted as the guiding posts to the reader. Devices (Spire Edge, BPTP, DDA) like turn to page no 3 , more at page communicated to the audience that the campaign is likely to conclude in the same edition of the newspaper where as copy devices like coming soon or broken dots (...) (Airtel, Big TV, Pantene, IP TV etc.) told the audience to keep looking every day for the next episode just like a daily serial on their favorite channel. Like newspapers, television teaser campaigns too, used the teaser device to connect all the teasers in one campaign. Presence of connecting copy devices was noted. Around $57 \%$ campaigns have used copy devices (words, phrases and symbols) to communicate that there is more to come in the campaign (Figure 5).

Commonly found copy devices are 'to be continued, coming soon, wait and watch' in television teasers .Since television advertising is ephemeral, it might be important to inform the viewing audience about the completeness or the incompleteness of the campaign. Amongst the fleeting images, teasers run the risk of losing themselves in the ad clutter. Use of teaser device also threw light on the episodic nature of these campaigns (Table 6).

A higher number of campaigns were not in form of one long story. $65 \%$ were based on one common idea in newspapers but presented through different incidents or vignettes. 57\% campaigns on television showed the teaser ads using different settings and characters to convey the campaign idea (Figure 6). Use of multiple celebrities was done to reinforce the same blind idea in the minds of the people. Different subjects and characters reiterated the same in all the teasers hammering the same teaser element in every ad. It can be inferred that continuing with a single story throughout the campaign may divert the audience attention from the brand and merely absorb them in the storyline itself taking the focus away from finding clues on brand identity left in every teaser before the final ad.

$43 \%$ campaigns on television were story based teasers with same characters and same plot without clues on name or identity of the brand till the final ad (Figure 6). Here, teaser campaign was created in three steps. One idea was conveyed through one story in an episodic manner where teaser1 acts as (part 1) leading to T2 as (part 2) and so on till the climax of the story in the final revealer. The teasers carried forward the story through the same characters expanding on the situation(s) bit by bit up to the final disclosure. The teaser campaign has a beginning, middle and an end. Such teasers resembled a film trailer or a promo on many occasions.

It may be said that teaser advertising is passing through the glorious phase of creative innovation. It will be presumptuous to underline the superseding popularity of either the episodic continuity of teasers or snapshots of embedded teaser elements at present (Table 7a).

The data shows that majority of the campaigns used conventional ad format for their final revealer advertisements in the newspaper. $61 \%$ of the revealer ads were conventional in nature followed by the picture based message format (20\%). Celebrities were also used in the final ad, though to a limited degree (14.3\%). Table 7 a shows that only NACO

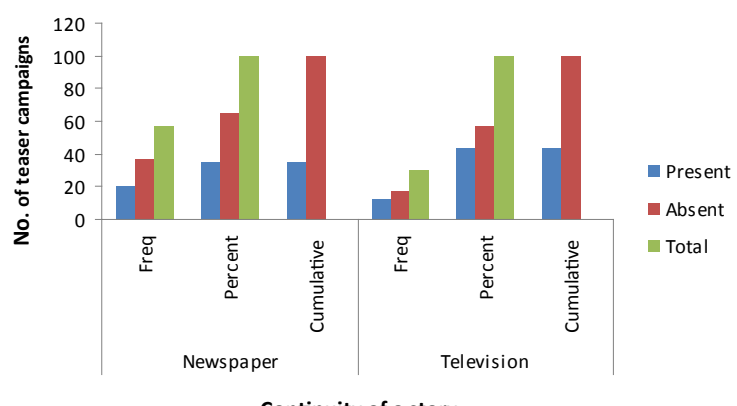

Continuity of a story

Figure 6: Distribution of teaser campaigns for continuity of story.

\begin{tabular}{|l|c|c|c|c|}
\hline Revealer Ad Format & Frequency & Percent & Valid Percent & Cumulative Percent \\
\hline $\begin{array}{l}\text { Conventional/feature } \\
\text { based }\end{array}$ & 34 & 60.7 & 60.7 & 60.7 \\
\hline Picture & 11 & 19.6 & 19.6 & 80.4 \\
\hline Comic strip & 3 & 5.4 & 5.4 & 85.7 \\
\hline Celebrity & 8 & 14.3 & 14.3 & 100.0 \\
\hline Total & 56 & 100.0 & 100.0 & \\
\hline
\end{tabular}

Table 7a: Frequencies of revealer format in teaser campaign in The Hindustan Times.

\begin{tabular}{|l|c|c|c|c|}
\hline Revealer Ad Format & Frequency & Percent & Valid Percent & Cumulative Percent \\
\hline Slice of life & 6 & 20.0 & 20.0 & 20.0 \\
\hline Vignettes & 5 & 16.7 & 16.7 & 36.7 \\
\hline Product demo & 5 & 16.7 & 16.7 & 53.3 \\
\hline Animation/ comic & 1 & 3.3 & 3.3 & 56.7 \\
\hline Celebrity/testimonial & 9 & 30.0 & 30.0 & 86.7 \\
\hline Announcement & 2 & 6.7 & 6.7 & 93.3 \\
\hline Imagery & 2 & 6.7 & 6.7 & 100.0 \\
\hline Total & 30 & 100.0 & 100.0 & \\
\hline
\end{tabular}

Table $7 \mathbf{b}$ : Frequencies of revealer format in teaser campaign teaser on Sony Entertainment Channel. 


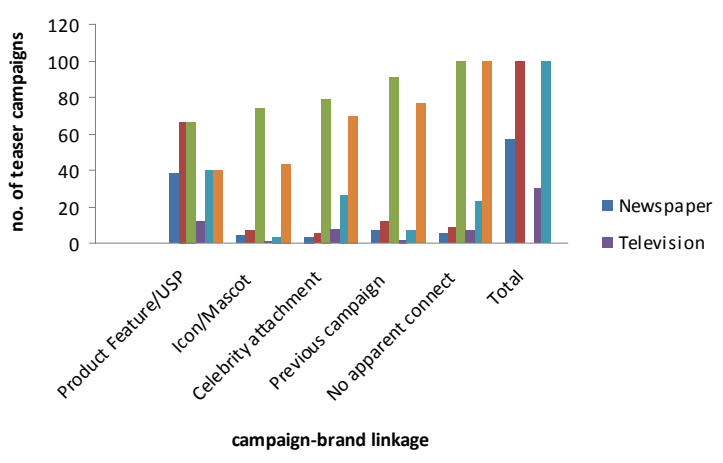

Figure 7: Distribution of teaser campaigns for campaign-brand link.

\begin{tabular}{|l|c|c|c|c|c|c|}
\hline & \multicolumn{3}{|c|}{ Newspaper } & \multicolumn{3}{c|}{ Television } \\
\hline Advertising Objectives & Freq & Percent & Freq & Percent & Freq & Percent \\
\hline Arousal & 30 & 52.6 & 52.6 & 12 & 40.0 & 40.0 \\
\hline Interaction & 4 & 7.0 & 59.6 & 7 & 23.3 & 63.3 \\
\hline Knowledge & 6 & 10.5 & 70.2 & - & - & - \\
\hline Audience Engagement & 15 & 26.3 & 96.5 & 7 & 23.3 & 86.7 \\
\hline Entertainment & 2 & 3.5 & 100.0 & 4 & 13.3 & 100.0 \\
\hline Total & & 57 & 100.0 & & 30 & 100.0 \\
\hline
\end{tabular}

Table 8: Frequencies of teaser objectives in The Hindustan Times and Sony Entertainment Channel.

used the comic strip format in its revealers. Other ad formats like the verse, problem solution, reason why etc. were not found in these campaigns. From the results, it can be assumed that revealers or the 'tell all' final ads are created to provide not only the information about the identity of the product and the advertiser but also give detailed information on its features, attributes and benefits.

It was observed that celebrity endorser and user testimonials $(30 \%)$ are the major execution formats used in television teasers. In some campaigns, other key common formats like the slice of life (20\%), vignettes $(17 \%)$ and demonstration format $(17 \%)$ were also used (Table $7 b)$. Since the difference in their use is less, it can be concluded that on television, the concept of the teaser decides the last ad format and there exists no specific rule or application of a particular message format in creating the 'tell all' ad. Thus it can be inferred that that revealer format depends upon the storyline and the characters in the campaign.

Table 8 shows that $53 \%$ of the campaigns in the newspaper aroused the audience's need for mystery and suspense. Communication message was intended to create a sensory feeling of thrill and excitement. Since teaser advertising works on the power of curiosity, arousal of audience was a popular communication objective. $26 \%$ campaigns engaged the audience into the concept, idea or story of the ad. It stressed that you cannot make audience curious yet passive. These was done to stimulate the audience into mass conversation. In this case, teasers aimed to poke the audience into action i.e. becoming a part of the sequence of parts campaign creating your answers raised by each teaser. It is similar to that of a brain teaser where the activity attempts to test the audience via communication. Two way communication in these campaigns created a scope for immediate or a delayed response. For e.g. look at the picture, tell the difference in the red label teasers. $11 \%$ campaigns worked on a conservative note, even in innovative creative type like teasers. Here, the objective was to provide detailed information about the brand in an unbranded campaign. Here the sender was cautious and aimed to spread knowledge about the brand leading to the final revelation about its identity. Few teaser campaigns (7\%) communicated with the audience to interact or open conversation about either the brand advertised or generic class of products. It was largely one way communication with messages shot as teaser questions leading to all the answers in the revealer. The element of mystery was superimposed by the attempt to tell the audience about the brand. Here, teasers expected the audience to be involved but passively till the end. 3.5\% campaigns were solely to entertain the consumer. Entertainment is slowly moving from other mass media like cinema to advertising as well. Use of humour, slice of life drama, hyperbole is largely to entertain the audience.

Television campaigns show that $40 \%$ are aimed at arousing public attention by creating mystery or suspense around the name or the type of the proactive response. Not necessarily feedback, these campaigns tended to direct the audience to use new media to participate in 'solving the puzzle'. url's and website addresses and names were given at the end of the advertisement. $23 \%$ merely communicated to the audience about various aspects of the product without naming it and $13 \%$ campaigns entertained the audience; induce fun, humour and enjoyment by telling a story (Figure 8).

From the results it is clear that teaser campaigns do not occur in isolation (Table 9). They are part of a larger ad plan. The data shows that most campaigns were created with visible and distinguishable linkages with the brand. $67 \%$ newspaper campaigns encapsulated the product feature or a tangible product benefit isolated as the unique selling proposition (USP) in the teaser ad. They had the USP of the product clearly encoded in the teaser element despite no cues on the brand identity. Teaser one after the other established the product feature in mass memory. In fact, the motive was to draw public attention to the USP of the brand and motivate the people to guess the likely brand or the product. Such a participatory communication activity worked to the advantage of the brand. Matching the mystery quotient to the product feature enabled the consumer to guess the brand correctly

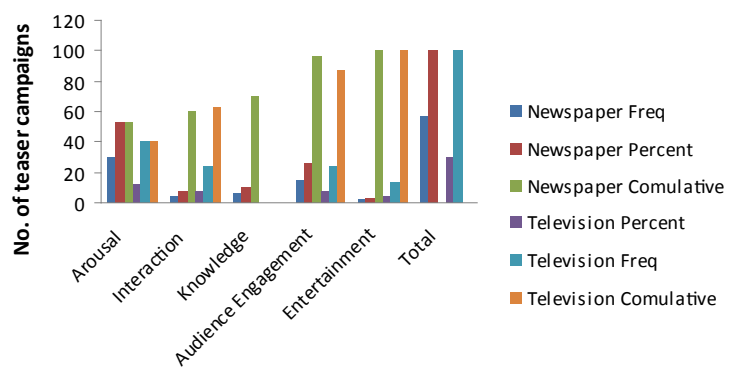

Objectives of teaser campaigns

Figure 8: Distribution of teaser campaigns for communication objectives.

\begin{tabular}{|c|c|c|c|c|c|c|}
\hline \multirow[b]{2}{*}{ Brand Linkage } & \multicolumn{3}{|c|}{ Newspaper } & \multicolumn{3}{|c|}{ Television } \\
\hline & Freq & Percent & Cumulative & Freq & Percent & Cumulative \\
\hline $\begin{array}{l}\text { Product Feature/ } \\
\text { USP }\end{array}$ & 38 & 66.7 & 66.7 & 12 & 40.0 & 40.0 \\
\hline Icon/Mascot & 4 & 7.0 & 73.7 & 1 & 3.3 & 43.3 \\
\hline $\begin{array}{l}\text { Celebrity } \\
\text { attachment }\end{array}$ & 3 & 5.3 & 78.9 & 8 & 26.7 & 70.0 \\
\hline Previous campaign & 7 & 12.3 & 91.2 & 2 & 6.7 & 76.7 \\
\hline $\begin{array}{l}\text { No apparent } \\
\text { connect }\end{array}$ & 5 & 8.8 & 100.0 & 7 & 23.3 & 100.0 \\
\hline Total & 57 & 100.0 & & 30 & 100.0 & \\
\hline
\end{tabular}

Table 9: Frequencies of linkage between the campaign and brand in The Hindustan Times and Sony Entertainment Channel. 
most of the times. The product feature serve like cue cards in a puzzle game. It led the consumer to the brand, it follows the principle that if the reader guesses it right, it becomes part of subconscious memory likely to create permanent recall and in case the guess is incorrect, the concept of the ad and brand remains alive.

The table shows that $12 \%$ campaigns had linkage to the previous campaign of the same product. It mainly occurred in brands using small cryptic teaser campaigns one after the other than opting for a single lengthy one. $9 \%$ campaigns had no connection with any previous campaign of the same product or brand.

Similar results were obtained from the television campaigns. $40 \%$ campaigns communicated the product feature or unique selling proposition through their teaser ads. While $27 \%$ were created to inform about the celebrity attachment/endorsement with the product, $23 \%$ campaigns had no apparent connect with the product or any previous campaign of the product. These campaigns were fully mysterious and were product specific leaving room for interpretation of the teaser ads independent of the intended message. Only 7\% campaigns showed linkage to the previous ad campaign in any which way (Figure 9). This shows that despite the need to careful, some teaser campaigns were fresh, original and novel. Even in creative advertising, lower level of communication objectives: awareness and knowledge were crucial (Table 10).

Advertising creates brands, all creative forms follows this maxim. $35 \%$ campaigns in the newspaper served established the brand presence for a new product to announce the brand's identity with the final revealer advertisement in the launch phase.

$30 \%$ campaigns created brand interest. These teaser campaigns by highlighting either the hidden or the induced differences between the competing products through a mysterious track or plot stimulated interest about the brand amongst the otherwise nonchalant audience. The results show that mature brands in product categories with

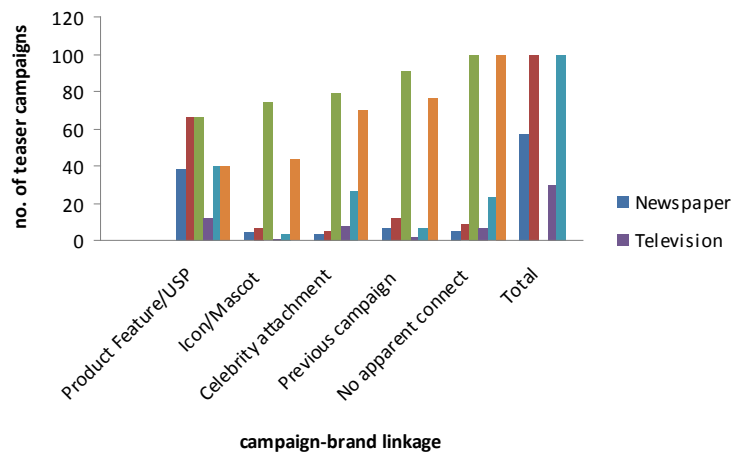

Figure 9: Distribution of teaser campaigns for campaign-brand link.

\begin{tabular}{|l|c|c|c|c|}
\hline & \multicolumn{2}{|c|}{ Newspaper } & \multicolumn{2}{c|}{ Television } \\
\hline Brand Building Functions & Freq & Percent & Freq & Percent \\
\hline Brand Presence & 20 & 35.1 & 9 & 30.0 \\
\hline Brand Interest & 14 & 24.6 & 8 & 26.7 \\
\hline Brand Extension & 7 & 12.3 & 7 & 23.3 \\
\hline Brand Image & 8 & 14.0 & - & - \\
\hline Category Need & 8 & 14.0 & 6 & 20.0 \\
\hline Total & 57 & 100.0 & 30 & 100.0 \\
\hline
\end{tabular}

Table 10: Frequencies of brand building functions by teaser campaigns in The Hindustan Times and Sony Entertainment Channel.

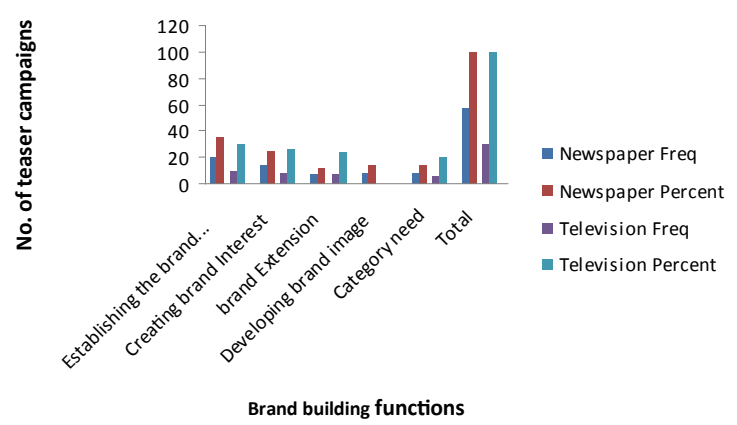

Figure 10: Distribution of teaser campaigns for brand building functions.

familiar, frequently used products, stimulated brand interest motivate action because of their ability to make the individual consumer open or curious about the brand. Existing products used teasers to revive the bored audiences towards the brand by creative messages that are entertaining and enjoyable. $13 \%$ were done for brand extension (Figure 10). Seemingly, manufacturers strategize to create individual brands instead of umbrella branding for the firm. Brand live cycles were extended via teaser ads by positioning the key brand associations of the line extension by launching or introducing a new extension i.e. a new product variant of the same product or a new type of product related to the existing category or belonging to a new class. This strategy is likely to build corporate reputation in the long run where product valuation aggregate and relationship with the organizations is taken into account. 9\% campaigns were involved in initiating long term function of developing brand image. Result show that teasers are not able to affect the image of the brand in themselves, yet can act as precursors to a long term strategy where the focus is not on tangible physical attributes but on perception of the people. Evidently teasers can only play a part in brand image, may be if it uses mascots or brand ambassadors in their message executions. $14 \%$ campaigns strived to create a new category need in the consumers. Teaser campaigns for health awareness and financial services were serving generic branding functions, where the entire type of good or service was focused upon.. $30 \%$ of the television campaigns served to introduce a new product in the market with the primary purpose of building brand identity through series of teasers and brand name presentation with the final revealer. 27\% campaigns were predominately leading to create brand interest. The creative quotient of these campaigns e.g. Videocon, Vodafone, ponds, dove etc was very high. $23 \%$ campaigns were done to extend the brand either by repositioning it or by starting a new line of the company. E.g. Maggi (three ad teaser campaign) for Maggi Bhuna Masala extended the brand Maggi further. 20\% were generic campaigns to create demand for a new type of good or service. No campaign was found to develop image at this stage.

\section{Conclusion}

Teaser campaigns are used not only in tangible goods but also in promoting services and idea highlight the spectrum of its reach and multiple roles. It was evident that its role extends beyond creating hype before a launch. The creative flexibility of storytelling in teaser ads makes it a perfect fit to perform the role of messenger, mediator and multiplier in the integrated marketing and communication environment. From the first 'hit' at the human mind to being a brand propeller in search of a perceptual space, its role is diverse. Existing models of Teaser advertising concentrated on curiosity and knowledge gap, whereas the findings of the study present that though, these two 
Citation: Trehan K, Maan GS (2013) Uses and Functions of Teaser Campaigns in Advertising and Promotion: A Content Analysis of Newspaper and Television Advertisements in India. J Mass Communicat Journalism 3:145. doi:10.4172/2165-7912.1000145

Page 8 of 8

remain the dominant antecedents of this creative form, other facets like entertainment, engagement and interaction are also important with respect to the vast marketing communication environment in India Evidently, lot of campaigns are being done to initiate a dialogue or a compelling conversation through teaser cues (verbal and visual) to rake the consumer brain and entice them into becoming reciprocal communicators instead of passive ones. Apart from the well known functions of entertainment and buzz creation, engagement has emerged a dominant function of teaser campaigns in the study. In a consumer empowered world, any advertising can work, only if it engages with the consumers at various levels in the communication process. The era of passive communication is over. Now the consumer wants to be a part of it even a part of the creative process. Teaser campaigns do just that. They take them along in a journey of promotional communication where the consumer carefully probes and preens to arrive at the appropriate product. With signposts at every stop, the consumer is properly guided in the journey by teaser messages.

\section{References}

1. Kover A (2010) Copywriters' Implicit Theories of Communication: An Exploration. Advertising edited by Chris Hackley Sage Publications 1: 79-108.

2. Mentioned in The Anatomy of Press Ads (2008) The Craft of Copywriting 59-60.

3. Yeshin T (1998) Integrated Marketing Communication: The Holistic Approach 156
4. Curiosity is an emotion that impels people to do things beyond logic and functional purpose. It makes us explorers and discoverers.

5. Shah K (2009) Advertising and promotion: An IMC perspective. Tata McGraw Hill Publications.

6. Hung K (2004) Framing Meaning Perceptions with Music: The Case of Teaser Ads, Journal of Advertising.

7. Satya M, Dilip S (2002) Managing the Power of Curiosity for Effective Web Advertising Strategies. Journal Of Advertising 31: 1-14.

8. Balbir Pasha HIVIAIDS Campaign is the talk of Mumbai ,PSI,2003. Html version of the file.

9. Re-launch of Frooti,-the Digen Verma Campaign, Part III, Marketing Communication Strategy Case Studies in Marketing Vol II , IMCR 2004.

10. Source : www.tamindia.com

11. The Hindustan Times was the most the circulated English daily newspaper and tops all the newspapers in terms of the advertising rates in Delhi in 2007-2008. Source: Audit Bureau of Circulation.

12. Sony Entertainment Network was at No.1 and 2 Position as per the television rating points in 2007-2008. Source: TAM India.

13. Ad Venture-an advertising intelligence package which provides media schedules of brands with the creatives of the ad campaign-be it on Cable \& Satellite TV Channels, Terrestrial Channels, regional, local and national newspapers and magazines.

14. Creative showcase contains Indian television commercials with date and the calendar year. 